\title{
A DOMESTICAÇÃO DOS CORPOS INFANTIS: EM DESTAQUE AS PRÁTICAS ESCOLARIZADAS NA EDUCAÇÃO INFANTIL
}

\author{
Viviane Sobh Souza, Universidade de São Paulo - USP, São Paulo - Brasil
}

Marcos Garcia Neira, Universidade de São Paulo - USP, São Paulo-Brasil

\begin{abstract}
RESUMO
A pesquisa investiga os mecanismos empregados para educação dos corpos em uma creche municipal. Analisa duas situações rotineiras da Educação Infantil - a festa de aniversário e a hora do sono - com o objetivo de identificar as formas como operam os dispositivos de governamento na infância. Na primeira, discute-se a forma de organização e os procedimentos que caracterizam a comemoração. $\mathrm{Na}$ segunda, analisam-se os procedimentos adotados na condução das crianças no momento do descanso. Ambos os casos foram interpretados mediante o confronto com o construto teórico foucaultiano. O estudo realizado permitiu identificar e compreender algumas contribuições da rotina institucional para constituição da subjetividade infantil, controlada por dispositivos de poder que domesticam os corpos, deixando-os dóceis e submissos às ordens sociais dominantes.
\end{abstract}

Palavras-Chave: Corpo; Educação infantil; Subjetividade.

\section{THE DOMESTICATION OF THE INFANT BODIES: FEATURED SCHOOLING PRACTICES IN EARLY CHILDHOOD EDUCATION}

\begin{abstract}
The research investigates the mechanisms used to educate the bodies in a community nursery. It analyzes two daily situations in an Infant Education - the birthday party and the nap time - in order to identify ways that forms of control take place in early years. At first, we discuss the type of organization and procedures that characterize the celebration. In the second, we analyzed the procedures used to manage children at resting time. Both cases were interpreted by the confrontation with the Foucault theorization. The study allowed us to identify and understand some contributions from the institutional routine to the configuration of the childhood subjectivity; controlled by the policies of power to domesticate the bodies, leaving them passive and submissive to the dominant social order.
\end{abstract}

Key-Words: Body control; Early childhood education; Subjectivity. 


\section{LA DOMESTICACIÓN DE LOS CUERPOS INFANTILES: PRÁCTICAS ESCOLARES DESTACADAS EN EDUCACIÓN INFANTIL}

\section{RESUMEN}

La investigación estudia los mecanismos utilizados para educar a los cuerpos en una guardería comunitaria. Se analizan dos situaciones cotidianas - la fiesta de cumpleaños y la hora de la siesta - el fin de identificar maneras en que las formas de control se llevan a cabo en los primeros años. En un primer momento, se discute el tipo de organización y procedimientos que caracterizan la celebración. En la segunda, se analizan los procedimientos utilizados para tratar a los niños en el momento de descanso. Ambos casos fueron interpretados por el enfrentamiento con la teorización de Foucault. El estudio nos permitió identificar y comprender algunas de las contribuciones de la rutina institucional en la configuración de la subjetividad infantil, controlada por las políticas del poder de domesticar los cuerpos, dejándolos pasivos y sumisos al orden social dominante.

Palabras-Clave: Cuerpo control; Educación infantil, Subjetividad. 


\section{INTRODUÇÃO}

A instituição social responsável pela educação de crianças de 0 a 5 anos nem sempre teve os mesmos objetivos ou se organizou da mesma maneira. Em meio à crescente urbanização e estruturação do capitalismo surgiram as creches no Brasil, as quais foram criadas prioritariamente para suprir as necessidades básicas da criança enquanto a mãe trabalhava. Inicialmente, as creches possuíam uma função puramente assistencialista, preocupando-se somente com o aspecto do cuidado da criança pequena, garantindo-lhe, mesmo que precariamente, alimentação e higiene. Mais recentemente, incorporaram novas preocupações, que extrapolam o cuidar para contemplar também a educação das crianças por meio de projetos pedagógicos específicos. Em muitos casos, a mistura dessas concepções é uma constante nas atividades cotidianas, ora tendendo para a educação, ora para o cuidado.

Inspirados na produção de Michel Foucault e nos trabalhos de Maria Isabel Edelweis Bujes, estranhamos aquilo que parece natural na rotina de uma instituição de educação infantil. A forma como as crianças são conduzidas nos variados momentos do dia chamou-nos a atenção negativamente e foi a partir deste incômodo que passamos a questionar como tal direcionamento influencia na subjetividade infantil.

Para pensar em algo tão enraizado na escola é preciso dispor-se a estudar e compreender "[...] como as crianças foram historicamente capturadas pelas malhas do poder, de como se estabeleceram políticas de verdade sobre elas, de como se deu a fabricação do sujeito moderno, de como operaram as máquinas que se encarregaram do governamento da infância". i:86

Governamento é a ação promovida por instituições, procedimentos, análises, reflexões, cálculos e táticas que permitem exercer o poder que tem por objetivo principal o controle da população. ii Michel Foucault conferiu-lhe esse sentido nos cursos que proferiu no Collège de France entre 1970 e 1971, cujas transcrições foram publicadas no livro "Vigiar e Punir". iii O conceito também mereceu um capítulo à parte na obra "Microfísica do Poder". iv

Conexões: revista da Faculdade de Educação Física da UNICAMP, Campinas, v. 12, n. 1, p. 107-125, jan./mar. 2014. ISSN: 1983-9030 
Transitando nas relações entre infância e instituição educativa, analisamos duas situações rotineiras em uma creche tomando como base as formas como operam os dispositivos de governamento. Durante um semestre letivo, foram realizadas observações sistemáticas do cotidiano institucional. Os dados foram registrados em diário de campo e submetidos à análise mediante o confronto com a teorização foucaultiana.

O procedimento permitiu discutir criticamente os aspectos que estruturam as práticas pedagógicas voltadas para a educação corporal, desconstruindo visões naturalizadas. As situações flagradas - festa de aniversário e hora do sono - envolvem um controle bem rígido do corpo e de seus movimentos, e foi a partir da visão dos corpos vigiados e regulados que interpretamos e problematizamos os procedimentos adotados pelas professoras. Emergiu daí a questão da dicotomia entre o cuidar e o ensinar na educação da infância, sendo que o segundo mostrou-se hierarquicamente acima do primeiro na estrutura institucional.

As duas situações eleitas contextualizam as práticas de educação corporal em que as relações de poder se sobressaem. O processo de análise permitiu identificar características comuns: o uso constante da disciplina para adequar e moldar o comportamento das crianças levando-as à docilidade; além da concepção de infância baseada em uma visão adultocêntrica de controle para adequação das crianças às normas socialmente impostas.

A maior dificuldade nesta empreitada foi indagar situações que se repetiam cotidianamente na instituição que acolheu a pesquisa. Outro obstáculo consistiu na falta de sensibilidade do olhar. Uma vez que estávamos aptos a enxergar somente o que já estava posto, enfrentamos o desafio de ver de outro modo, mudando perspectivas e conceitos.

Diante dos empecilhos é preciso considerar que “[...] existem momentos na vida onde a questão de saber se se pode pensar diferentemente do que se pensa, e perceber diferentemente do que se vê é indispensável para continuar a olhar ou a refletir", v:13

Conexões: revista da Faculdade de Educação Física da UNICAMP, Campinas, v. 12, n. 1, p. 107-125, jan./mar. 2014. ISSN: 1983-9030 


\section{A docilização dos corpos na educação infantil}

Michel Foucault estudou e refletiu sobre muitos aspectos da constituição social, enxergando-os a partir de outro olhar, sob outras perspectivas. A instituição escolar foi um de seus cenários críticos, por ser palco de vigilância constante através de diversos mecanismos de controle, utilizados para buscar a normalização e a padronização dos indivíduos.

Estes mecanismos não estão presentes somente na escola, ao contrário disso, podem ser encontrados em toda a nossa sociedade, a qual é organizada minuciosamente para vigiar os seus sujeitos, exercendo o tempo todo normatizações e adequações sobre seus corpos. Mesmo aqueles indivíduos que fogem dos padrões são capturados de alguma forma. Afinal, “[...] em qualquer sociedade, o corpo está preso no interior de poderes muito apertados, que lhe impõem limitações, proibições ou obrigações". 2:126

A ideia de vigilância é descrita por Foucault através do conceito de panoptismo, que envolve principalmente a ideia do 'olhar do outro'.

O dispositivo panóptico organiza unidades espaciais que permitem ver sem parar e reconhecer imediatamente. Em suma, o princípio da masmorra é invertido; ou antes, de suas três funções - trancar, privar de luz e esconder - só se conserva a primeira e suprimem-se as outras duas. ${ }^{2: 165}$

Nesse sistema, "a visibilidade é uma armadilha". $2: 165$ No âmbito social, o dispositivo visa garantir o bom funcionamento de alguns mecanismos de controle, como a disciplina, uma vez que as pessoas distribuídas em diversos tempos e espaços, por meio das redes invisíveis, não conseguem saber quando estão sendo vigiadas, por isso, internalizam a disciplina e esta acaba ganhando ares de naturalidade.

Os estudos de Foucault têm por base a atuação sofisticada e sutil das relações de poder vigentes na sociedade, estas, por sua vez, disciplinam e controlam os indivíduos segundo o jogo social dominante. A ideia de que os indivíduos são controlados nas 
minúcias e nos detalhes nos remete a outra consideração foucaultiana, a qual nos apresenta o corpo como algo manipulável, que "[...] pode ser submetido, que pode ser utilizado, que pode ser transformado e aperfeiçoado". 2:126

As tecnologias de vigilância constante, distribuição continuada de microssanções e o exercício do exame se encontram vivas nas instituições de educação infantil, operando de modo constante e contínuo, visando controlar e moldar as crianças. ${ }^{1}$

Com a Idade Moderna, as instituições sociais deixaram de ser locais de suplício para tornarem-se ambientes que visam criar 'corpos dóceis'. A mudança trouxe uma vantagem social e política, pois o suplício enfraquecia e destruía os recursos vitais dos indivíduos, ao contrário da docilização, a qual torna os corpos mais produtivos e úteis.

O trabalho de Foucault aprofundou a compreensão de que a nova paisagem social e os novos raciocínios populacionais que se consolidaram a partir do século XVIII, estabeleceram um novo lugar para a infância. ${ }^{\text {vi }}$ Com a substituição do poder soberano outra forma de governar, a sociedade organizou-se sob novas bases, desencadeando mudanças nas relações entre adultos e crianças.

\footnotetext{
Neste quadro em que se dá um grande aumento populacional, em que ocorre uma expansão da base monetária e um notável aumento da produção agrícola - processos estes que agem de forma simultânea e se reforçam mutuamente - emerge o problema da população que tem conexão estreita com o "desbloqueio da arte de governar". O modelo da família que orientava até aí a arte de governar perde sua potência. O objetivo do governo passa a ser a população. É preciso gerir a vida dos indivíduos, agir diretamente sobre a população: estimular ou bloquear a taxa de natalidade, prevenir a mortalidade, controlar os fluxos populacionais, entender a população como sujeito de necessidades e aspirações. A família, de modelo fundamental, passa a se constituir em instrumento privilegiado para o governo das populações. ${ }^{6}$
}

O poder soberano exercido pela ameaça de causar a morte através das instâncias de confisco: extorsão de produtos, de bens, de serviços, de trabalho e de sangue imposta aos súditos transformou-se em garantir, sustentar, reforçar, multiplicar a vida e pô-la em ordem. O direito à vida se impôs. Com isso, os novos alvos do poder passaram a ser os corpos dos indivíduos e o investimento na vida através da intervenção direta ou indireta visou a construção do corpo obediente e produtivo, ou seja, o corpo máquina.

Conexões: revista da Faculdade de Educação Física da UNICAMP, Campinas, v. 12, n. 1, p. 107-125, jan./mar. 2014. ISSN: 1983-9030 
O poder necessitava ainda exercer-se num outro âmbito, mais amplo, sobre o corpo enquanto suporte de processos biológicos, no sentido de garantir a vida, a saúde, a proliferação da espécie. Estabeleceram-se intervenções e controles para regular tais processos e as condições para fazê-los variar, o que fez desenvolver a organização do poder sobre a vida, o biopoder. Assim, as crianças transformaram-se em alvo privilegiado das operações que administravam corpos com vistas à gestão calculista da vida. Elas tornaram-se objeto de ações políticas, de intervenções econômicas, de campanhas ideológicas de moralização e de escolarização, de uma intervenção calculada. ${ }^{1}$

Neste emaranhado de relações, enuncia-se a disciplina, a qual se dá

Através de processos múltiplos, mínimos, de origens diferentes, de localizações esparsas, que se repetem, se sobrepõem, que se apoiam mutuamente, que entram em convergência, que operam sobre os corpos e que acabam por esboçar uma estratégia geral de ação. ${ }^{1: 112}$

A disciplina tornou-se um método indispensável de controle minucioso dos corpos, evidenciando um binômio de docilidade/utilidade, esquadrinhando o espaço, o tempo e os movimentos. "O que as disciplinas visam através de sua ação é a paulatina incorporação destas formas 'apropriadas' de conduzir-se, de pensar e de sentir, sutilmente construídas através das táticas que empregam”. 1:111

Tal controle não é exaltado a partir de práticas coercitivas, de sujeição como ocorre com as fórmulas históricas de dominação, ao invés disso, este processo conta com a

[...] preservação de uma certa autonomia, do próprio corpo, para aqueles que com ela se relacionam. A autonomia seria perpassada, entretanto, por uma política de coerções sutis aplicada sobre o corpo em todos os seus elementos, gestos e comportamentos. ${ }^{1: 112}$

É por meio desse recurso que todas as normas e sanções sociais vão sendo introjetadas nos indivíduos tornando as práticas de controle naturais e invisíveis aos nossos olhos. "Daí o efeito mais importante do Panóptico: induzir no detento um estado consciente e permanente de visibilidade que assegura o funcionamento automático do poder" 3:165 Sabendo que está sendo olhado e avaliado, o indivíduo se autocontrola e procura seguir os padrões sociais impostos.

Conexões: revista da Faculdade de Educação Física da UNICAMP, Campinas, v. 12, n. 1, p. 107-125, jan./mar. 2014. ISSN: 1983-9030 
Com o advento da modernidade, as normas e sanções são estipuladas a partir do olhar adulto, no qual os comportamentos sancionados já se manifestam automaticamente. A tendência é inculcar nas crianças menores as permissões e as interdições engendradas pela disciplina para que estas se coloquem como intencionais e controláveis em seus comportamentos. ${ }^{1}$ A criança, vista como selvagem, precisa urgentemente ser moldada e civilizada. É a partir do século XVIII que se estabelecem " [...] as condições para que o adulto e criança se diferenciem, numa operação que se constitui a justificativa para a intervenção familiar e para a prática da educação institucionalizada", 1:33 sendo o primeiro sempre colocado hierarquicamente acima da segunda.

As circunstâncias sociais, políticas e econômicas que marcam a Europa moderna, decorrentes especialmente de uma perspectiva iluminista no modo de conceber o saber e a razão humana, encaminham novas formas de compreender os papéis dos sujeitos e das instituições sociais. Os sujeitos passam a ser concebidos como seres reflexivos e autoconscientes, capazes de crítica e intervenção nas instituições sociais. Progresso e razão aparecem intimamente associados. Assim, a intervenção sistemática e planejada nas instituições sociais passa a ser considerada desejável como fator de progresso social e desenvolvimento individual.

É nesse bojo de condições que se engendra a escola moderna. Contexto em que eclodem espaços próprios para a educação; um corpo de especialistas, teorias e tecnologias específicas, além da obrigatoriedade. ${ }^{6}$

Essa necessidade de regulação estatal e de controle explica o surgimento de práticas de educação das famílias, bem como a definição de espaços próprios para a educação das crianças. Nesse momento, a força moralizadora do fanatismo religioso, católico e protestante, se associa ao projeto da Modernidade. Os tratados da época exaltam a obediência, o respeito, o amor filial e o papel da mulher. Nesse contexto, se instala uma nova compreensão das relações de parentesco e um significado diferenciado de infância.

É nesse ambiente que se constituem os novos raciocínios sobre a educação da criança pequena: sua desejabilidade, seus limites, suas potencialidades. Daí por diante cresce a Conexões: revista da Faculdade de Educação Física da UNICAMP, Campinas, v. 12, n. 1, p. 107-125, jan./mar. 2014. ISSN: 1983-9030 
produção científica sobre a criança. "Os corpos e as mentes infantis tornam-se objeto da ciência. As crianças têm seu desenvolvimento monitorado, suas ações, no plano concreto e no plano simbólico, esquadrinhadas para delas se deduzir as operações mentais que lhes estariam servindo de suporte". 6:05 Os saberes então produzidos, ao mesmo tempo em que descrevem os processos pelos quais passam os sujeitos infantis no decorrer do seu desenvolvimento (descrevendo o que é normal e desejável neste desenvolvimento), servem de referência para observação e avaliação dos pequenos. $\mathrm{Ou}$ seja, esses saberes ou disciplinas estão implicados na produção dos mesmos sujeitos que buscam descrever. "Eles servem de parâmetro para produzir a regulação e a normalização que estão presentes no que se considera como 'a boa pedagogia",. 6:05

Isso nos coloca diante da necessidade de compreender a infância e a educação escolar como produzidas de acordo com interesses políticos, sendo a infantilidade e o corpo operados como um dispositivo técnico-histórico, como uma máquina. É importante observar como se entrecruzam os dispositivos que constituem a infância (ou um conceito sobre ela) e as práticas específicas, ou estratégias, que se dão na sua educação e/ou escolarização. Tal compreensão evidencia a necessidade de se considerar as práticas presentes na Educação Infantil como formas de governamento.

A Educação Infantil, enquanto dispositivo de constituição da infantilidade, exerce uma função estratégica. Ela materializa uma intervenção racional e organizada sobre a constituição dos sujeitos, que pressupõe a manipulação de relações de poder. "Pode operar tanto para maximizar determinados resultados quanto para opor-se ou bloquear

aqueles indesejados". 6:05 O que significa que, como qualquer dispositivo, a educação infantil se inscreve na ordem do poder, por isso constitui veículo de produção de modos de ser e agir.

\section{A festa de aniversário}

Ao pensarmos em uma festa nos vêm à mente diversão, movimento, interação, prazer e sorrisos. Sua forma de expressão prioritária é a linguagem corporal. Ainda mais no caso dos bebês, cuja comunicação se dá predominantemente pelo corpo através dos gestos, do movimento, da inquietação.

Conexões: revista da Faculdade de Educação Física da UNICAMP, Campinas, v. 12, n. 1, p. 107-125, jan./mar. 2014. ISSN: 1983-9030 
Dada a importância da festa de aniversário em nossa cultura, principalmente nos primeiros anos de vida, muitas instituições de Educação Infantil organizam-na para as crianças, porém cada escola tem a liberdade para realizar o evento ao seu modo. $\mathrm{Na}$ situação investigada, o evento pode ser caracterizado brevemente como uma festa organizada para muitas pessoas, dispondo de pouco tempo para sua realização, com um espaço mal distribuído, o qual limita os movimentos e a diversão.

No caso observado, a festa está centrada apenas no ato de comer, o qual também é controlado. Embora mensal, a atividade não é sequer mencionada no projeto pedagógico da instituição, portanto, seus objetivos educacionais não estão explicitados. É realizada com intuito comemorativo. Sendo assim, depreende-se que sua principal intenção seja proporcionar diversão às crianças.

Há muitas considerações a fazer quanto ao espaço que é oferecido para as crianças desfrutarem do momento festivo, em especial sobre o posicionamento das crianças menores. É possível enxergar claramente a imobilidade a que são submetidas, presas literalmente em cadeirões, de maneira a impedir seus movimentos e facilitar o controle por parte das professoras. Outro aspecto que merece críticas é o local em que os cadeirões são posicionados, mais ao fundo do pátio, em círculo, distantes das outras crianças e do bolo.

Observando a cena, a impressão é que os pequenos não se sentem parte da festa, apenas constituem a decoração.

Tal organização assemelha-se às operações de vigilância:

[...] visam fixar e tornar o indivíduo imediatamente acessível, identificar presenças e ausências, saber onde e como encontrar cada um, estabelecer ou bloquear fluxos de comunicação, poder vigiar o comportamento dos indivíduos para sancioná-los ou medir suas qualidades. $^{1: 130}$

No caso da festa de aniversário, o modo como o espaço é organizado não concede nenhuma liberdade às crianças. Afinal, “[...] é preciso que cada indivíduo esteja no seu lugar $[\ldots] " 1: 130$ para que seja observado e controlado de acordo com as regras impostas. O espaço restrito e limitado reduz as possibilidades das crianças se machucarem ou de fazerem algo que não foi previsto pelos adultos, sendo estes os principais fatores a Conexões: revista da Faculdade de Educação Física da UNICAMP, Campinas, v. 12, n. 1, p. 107-125, jan./mar. 2014. ISSN: $1983-9030$ 
serem garantidos. O que fica implícito é a visão de que as crianças, ao ficarem soltas "[...] se tornam muito menos controláveis, tornando o processo menos econômico e o apelo à violência mais atraente".1:131

Observa-se que as crianças vão sendo colocadas em uma posição inferior em relação aos adultos, evidenciando uma necessidade de manter a hierarquia social estabelecida.

O traço distintivo do poder é que alguns homens possam mais ou menos integralmente determinar a conduta de outros homens - ainda que não de maneira exaustiva ou coercitiva (...) O governo dos homens pelos homens - formem eles grupos modestos ou importantes, quer se trate do poder dos homens sobre as mulheres, dos adultos sobre as crianças, de uma classe sobre a outra, ou de uma burocracia sobre uma população - supõe uma determinada forma de racionalidade e não uma violência instrumental $[\ldots]^{1: 76}$

Na instituição de educação infantil observada é concedida ao adulto a legitimidade e autoridade social de decidir o que é certo e o que é errado, o que é bom e o que é ruim. E a partir deste cenário as crianças vão constituindo suas subjetividades. Na visão de Foucault, ${ }^{4}$ esse mecanismo poderá levar as crianças a introjetarem pouco a pouco a submissão e passividade, permitindo que os adultos guiem suas condutas e posturas, dizendo-lhes o que é certo e o que é errado. Paulatinamente, segundo o filósofo francês, poderão aprender a controlar gestos e reprimir impulsos e desejos e, por esse meio, vão compreendendo as regras do jogo social que carregarão consigo.

$\mathrm{Na}$ situação analisada, as crianças são completamente privadas de vivenciarem e explorarem o ambiente que lhes foi oferecido, dificultando seu envolvimento e a atribuição de sentido ao momento. Elas se encontram limitadas ao seu pequeno espaço, estipulado pelos adultos, e a olhar para os lados. Apesar de ainda não se expressarem por meio da fala, conseguem deixar nítido seu desconforto, sua inquietação e até sua irritação, através de choros constantes, gritos e tentativas de sair dos cadeirões. As expressões de aversão são completamente opostas ao que se espera ver em uma festa. Nesta situação fica claro que "o polo do adestramento volta-se para o corpo-máquina: treinando-o, reforçando suas aptidões, tirando o máximo de suas forças, garantindo sua integração em sistemas de controle eficazes e econômicos". 1:33 
Há também o controle do tempo que atravessa os corpos e interfere no ato de comer durante a festa. Segundo Foucault, ${ }^{3: 127}$ o horário “[...] é uma velha herança. As comunidades monásticas haviam sem dúvida sugerido seu modelo estrito. Ele se difundiria rapidamente." $\mathrm{Na}$ instituição escolar o controle do tempo está enraizado através da rotina, que fragmenta o dia em pequenos espaços de horários com atividades supostamente previstas. A festa não é diferente, uma vez que foi planejada para durar no máximo 40 minutos. Neste tempo todos devem tirar fotos, permanecerem organizados, comerem e beberem o que lhes for servido e, ao final, retornarão às salas de aula para dar seguimento à rotina. Para cumprir o tempo estipulado, as professoras servem as crianças com rapidez. Em semelhança à linha de produção, cada uma exerce uma função no tempo exato. Quando uma criança se recusa a comer ou faz "manha", a professora insiste uma vez e, então, passa para a próxima. A possibilidade de comer sozinha ou pelo menos tentar não existe, pois ainda não consegue alimentar-se conforme o que se espera socialmente. $\mathrm{O}$ ato de comer também exige um disciplinamento do corpo, pois " [...] para tornar os gestos mais eficientes, é imperativo que a ação esteja em sintonia com o corpo como um todo e com o objeto a ser manipulado. Um corpo disciplinado serve de base para um gesto eficiente." 1:133

Alguns profissionais não apreciam a comemoração do aniversário. A justificativa é o fato das crianças ficarem agitadas, irritadas, por atrasar a rotina, pela dificuldade de deslocamento etc. Tudo se vincula aos interesses e dificuldades dos adultos e em nenhum momento é considerado o mal-estar que as crianças sentem ao serem colocadas na imobilidade. Não há qualquer reflexão sobre o que está acontecendo. Por estarem absorvidas no cuidado, as professoras não conseguem interpretar a linguagem corporal infantil.

É importante repensar a organização deste momento de forma a propiciar às crianças o prazer da confraternização e a diversão da festa, onde possam interagir com o ambiente e com as pessoas. Todos os momentos na Educação Infantil deveriam ser enriquecedores. Para tanto, não seria necessário tanto controle. Uma prática mais reflexiva e aberta seria muito bem-vinda, afinal, as crianças estão explorando e conhecendo o mundo.

Conexões: revista da Faculdade de Educação Física da UNICAMP, Campinas, v. 12, n. 1, p. 107-125, jan./mar. 2014. ISSN: 1983-9030 


\section{A hora do sono}

O momento do sono é padronizado para todas as crianças da creche, ocasião em que são obrigadas a dormir. A permanência dessa prática ao longo do tempo não deixa de surpreender, pois, um dos documentos norteadores das ações pedagógicas na Educação Infantil há mais de uma década já alertava que

[...] o atendimento das necessidades de sono e repouso, nas diferentes etapas da vida da criança, tem um importante papel na saúde em geral e no sistema nervoso em particular. As necessidades e o ritmo de sono variam de indivíduo para indivíduo, mas sofrem influências do clima, da idade, do estado de saúde e se estabelecem também em relação às demandas da vida social. ${ }^{\text {vii:59 }}$

Nas suas recomendações é bem explícito quando defende ser "[...] importante que haja flexibilidade de horários e a existência de ambientes para sono ou para atividades repousantes, pois as necessidades das crianças são diferentes". 7:60 Orientações oficiais mais recentes apontam para a singularidade da necessidade de descanso. "Procuramos respeitar o ritmo fisiológico da criança: no sono, nas evacuações, nas sensações de frio e calor". viii: 15

O caráter singular não é considerado na instituição de ensino investigada, na qual, durante as observações realizadas dentro das salas, identificamos procedimentos homogeneizantes que oportunizam às crianças um único momento coletivo de descanso. Mesmo aquelas que resistem, são obrigadas a permanecer nos colchões, de modo que ao menos o comportamento caracterize o ato de dormir, mostrando assim obediência às normas previamente estabelecidas.

É interessante destacar a exigência da imobilidade, quietude e que, preferivelmente, estejam deitadas em decúbito ventral ou lateral, posições que a instituição considera corretas. Quando alguma criança demonstra impaciência ou ansiedade por meio do balançar de pernas, braços ou balbucios, logo é repreendida e orientada a adotar a maneira estipulada e esperar a chegada do sono.

Além da repreensão, também são utilizadas outras técnicas para imobilizar quem se recusa a dormir. Toques no rosto ou nas costas, carinhos na cabeça ou pequenos "tapas" no bumbum são utilizados para aquietá-las e provocar o sono. Quando acordam antes 
do tempo pré-determinado são estimuladas a seguir as "regras do jogo" para que não acordem as colegas ou causem a desordem na sala, quebrando a rotina que deve ser seguida. As crianças que dormem menos que o estipulado devem permanecer em seus lugares, imóveis, sem se expressar-se ou fazer outras atividades, o que as leva a esperar ansiosamente pelo acender das luzes, indicando o fim do horário do sono. Muitas esperam o momento cantando baixinho, tentando pegar brinquedos ou se revirando nos colchões, mas sempre são repreendidas: "Ainda não é hora de acordar, fica quieto/a", "Deita neste colchão e dorme mais um pouco", como se isso fosse automático, ou simplesmente alcançado por um sonoro "psiu".

Quando as crianças dormem além do tempo previsto, são despertadas para que as atividades prossigam. Ou seja, o momento de despertar atende também a racionalidade institucionalmente imposta, basta verificar a frase dita por uma coordenadora pedagógica para chamar a atenção de uma professora cujas crianças permaneciam dormindo depois do horário ilustra: "O que a diretora irá pensar se vir a tua sala assim? Ela vai pensar que você não está trabalhando". Isso indica que se cumprido até o tempo determinado o sono é um momento importante e indiscutível da rotina, mas ao ser extrapolado, se transforma em tempo ocioso e prejudicial ao desenvolvimento infantil. $\mathrm{Na}$ instituição escolar não é permitido o ócio, por isso "[...] procura-se também garantir a qualidade do tempo empregado: controle ininterrupto, pressão dos fiscais, anulação de tudo o que possa perturbar e distrair; trata-se de construir um tempo integralmente útil". 2:127

Todas essas estratégias controladoras denunciam o paradoxo entre os discursos pedagógicos que “[...] têm construído para elas 'posições de sujeito' que se sustentam em uma determinada concepção de sujeito infantil [... $]^{, 1: 27-28}$ e os discursos correntes na prática que, ao contrário, enunciam as crianças como selvagens e insondáveis que precisam ser controladas e dominadas para aprender a viver na sociedade segundo suas normas. Além disso, evidenciam que os corpos que aqui estão sendo enunciados são "vigiados no detalhe"1:35 sendo consideradas e moldadas as minúcias de seus gestos.

Conexões: revista da Faculdade de Educação Física da UNICAMP, Campinas, v. 12, n. 1, p. 107-125, jan./mar. 2014. ISSN: 1983-9030 
A padronização do momento do descanso possui reflexos de uma organização baseada nas "ambições" do sonho militar da sociedade do século XVIII, descritas por Foucault. ${ }^{2: 142}$

[...] sua referência fundamental era não ao estado de natureza, mas às engrenagens cuidadosamente subordinadas de uma máquina, não ao contrato primitivo, mas às coerções permanentes, não aos direitos fundamentais, mas aos treinamentos indefinidamente progressivos, não à vontade geral, mas à docilidade automática.

Foucault descreve a disciplina como a arte das distribuições nos tempos e espaços, limitando a liberdade dos indivíduos a partir da normalização. Ele destaca o minucioso esquadrinhamento nas instituições, inclusive a escolar, a qual visa homogeneizar os indivíduos segundo os padrões sociais dominantes.

O corpo singular torna-se um elemento, que se pode colocar, mover, articular com outros. Sua coragem ou força não são mais as variáveis principais que o definem, mas o lugar que ele ocupa, o intervalo que cobre, a regularidade, a boa ordem segundo as quais opera seus deslocamentos. ${ }^{2: 138}$

A disposição dos corpos pela sala no momento do sono, organizados de modo a manter a ordem para que tudo ocorra conforme o esperado caracteriza a dissolução da singularidade que deixa de ser vista em si mesmo, uma vez que "a tática disciplinar estabelece as conexões entre o indivíduo e o todo do qual faz parte, se situa sobre o eixo que liga o singular e o múltiplo". 1:113 A lógica de organização do espaço escolar é criada a partir de um esquadrinhamento do comportamento das crianças, as quais são observadas detalhadamente. No momento do sono, em específico, a observação cria estratégias de manutenção da ordem. Ao perceber que certa criança é mais agitada para dormir, a professora a conduz para o canto da sala evitando que incomode as demais. Trata-se de uma tática que examina e coage, considera o detalhe, o qual é constantemente observado e articulado no espaço escolar para que se mapeie a melhor maneira de estruturá-lo, sempre visando à manutenção da disciplina. Nesta perspectiva, vemos que a organização da Educação Infantil enquanto instituição social

[...] não visou apenas a aquisição de conhecimentos ou experiências significativas para o indivíduo e, sim, uma prática muito mais abrangente que cuida da produção de comportamentos desejáveis, o que coloca a escolarização num conceito bem mais amplo daquele comumente descrito. ${ }^{\mathrm{ix}: 37-38}$

Conexões: revista da Faculdade de Educação Física da UNICAMP, Campinas, v. 12, n. 1, p. 107-125, jan./mar. 2014. ISSN: 1983-9030 
É necessário também analisar os discursos veiculados diariamente que defendem a hora do sono na rotina: "As crianças precisam dormir senão elas não prestam atenção em nada e só choram"; "Se as crianças não dormem ficam chatas, brigam mais e não se concentram em nenhuma atividade"; "Fulano não quer dormir, depois vai ficar enjoado". Falas que circulam na instituição, demarcando informalmente a importância que as profissionais atribuem ao momento. Quando ressaltam consequências negativas como irritabilidade, falta de concentração e disposição para as atividades do dia, malestar que pode provocar choros excessivos, estão, na verdade, justificando a coerção empregada. Afinal, restringindo ao máximo a possibilidade do surgimento desses distúrbios, zelam pelo bom andamento da rotina. $\mathrm{O}$ sono é visto como um dispositivo para facilitar o controle das crianças nos momentos de vigília. Consequentemente, entende-se que as crianças que não dormem são menos dóceis. Ignora-se que obrigar uma criança a dormir muitas vezes acaba gerando mais desconforto e irritação.

O que se evidencia é que as professoras estão mais preocupadas com o desempenho das crianças nas atividades que serão realizadas durante o dia do que com o seu bem-estar. Não há qualquer preocupação em ouvi-las, pois vigora uma visão consolidada de que o adulto é superior à criança, que sabe o que é melhor e precisa ser obedecido.

A engrenagem institucional não busca o domínio do corpo do outro através da coerção, mas sim através de normas e regras pré-estabelecidas que internalizadas socialmente. "Deste modo, a finalidade das disciplinas é a fabricação de corpos submissos e exercitados, "corpos dóceis", 1:111 Ou seja, o processo de autodisciplinamento acaba conferindo certa invisibilidade e naturalidade às condutas construídas e moldadas com o passar do tempo.

O capitalismo requer pessoas aptas e domesticadas em prol do mercado. A sociedade traça um perfil humano considerado correto, transformado em referência de sucesso e aceitação. Ao aceitar passivamente a função e a responsabilidade de formar para essa sociedade, a escola ensina as crianças a serem disciplinadas, justificando uma formação para a vida adulta, para serem boas cidadãs. Não é por acaso que as professoras da

Conexões: revista da Faculdade de Educação Física da UNICAMP, Campinas, v. 12, n. 1, p. 107-125, jan./mar. 2014. ISSN: 1983-9030 
creche dizem que é de pequeno que se impõe limites e que se isso não for feito a criança terá problemas para conviver em grupo.

Em pouco tempo, o que se vê são crianças condicionadas à rotina imposta. Isso causa boa impressão na instituição, pois aquelas que correspondem às exigências são consideradas obedientes e suas professoras são vistas como profissionais eficientes. A eficácia dessa maquinaria não pode ser desprezada uma vez que cumpre seu propósito inicial, o de manter a disciplina e a ordem formando pessoas obedientes. As restrições que inicialmente eram tidas como torturantes passam a ser naturais, necessárias e indispensáveis. As crianças que antes se recusavam a dormir e utilizavam de diversas estratégias para fugir da coerção, em pouco tempo simplesmente pegam sua chupeta, seu paninho e se deitam sem reclamar nem causar maiores problemas.

\section{CONSIDERAÇÕES FINAIS}

$\mathrm{Na}$ sociedade em que vivemos, a liberdade articula-se ao poder, é uma liberdade controlada e vigiada sutilmente. Isso ficou visível na análise de duas situações específicas da rotina de uma instituição dedicada à educação da infância: a festa de aniversário que ocorre mensalmente e o momento do sono. Foi possível compreender as contribuições desse processo na educação corporal e, consequentemente, na constituição da subjetividade infantil.

Apesar das crianças realizarem diversas atividades com formatos e intenções variadas (brincadeiras, histórias, banho, momentos livres, alimentação etc.), naquelas analisadas pelo presente estudo (festa de aniversário e hora do sono) não identificamos ocasiões em que a individualidade ou livre expressão tiveram espaço. As professoras parecem reproduzir acriticamente formas de lidar com as crianças. Modificá-las significaria a instauração de novas configurações institucionais, que seriam, muito provavelmente, consideradas impróprias e ineficazes. Conforme informações obtidas junto às professoras, praticados na instituição há anos de maneira uniforme e sem questionamentos, os procedimentos adotados para a festa de aniversário e a hora do sono constituem-se em meios eficazes não somente para o controle do corpo, mas também e principalmente, para o seu disciplinamento.

Conexões: revista da Faculdade de Educação Física da UNICAMP, Campinas, v. 12, n. 1, p. 107-125, jan./mar. 2014. ISSN: 1983-9030 
Enquanto mecanismo para a educação corporal, a creche não descuida da disciplina, a qual visa garantir que as crianças aprenderão o funcionamento da "maquinaria social". A disciplina é tão necessária à manutenção da ordem que na situação analisada é evidente o olhar panóptico. A vigilância no momento do descanso faz com que as crianças permaneçam deitadas, sem expressar reações. No caso da festa de aniversário, a disposição dos cadeirões no espaço garante a supervisão e a restrição drástica da mobilidade.

Mediante o olhar dominante a criança é constantemente levada a produzir os comportamentos socialmente esperados, criando uma busca incessante pela formação de "um sujeito que se autovigia, que se autoavalia e que se narra ou se confessa".1:147 Porém, por vezes, transgride as normas, brincando com novas formas de ser e se portar e por isso é vista como inferior, em formação, que precisa ser civilizada. O comportamento infantil é mal visto pelos adultos, que utilizam diversas punições para corrigi-lo, levando-as a adotar um estado passivo, de obediência.

Essa passividade, aceita como natural e inevitável deve ser combatida no âmbito educacional, por meio de questionamentos, problematizações, sugestões de novas práticas e discussões acerca do tema, com vistas a desestabilizar algo tão enraizado na cultura escolar. Apenas assim, conseguiremos contribuir com a formação de sujeitos mais críticos, capazes de refletir e discutir sua própria realidade, mesmo tendo consciência que a domesticação dos corpos faz parte de um macroprocesso que engloba outros âmbitos da sociedade.

\section{REFERÊNCIAS}

${ }^{1}$ BUJES, M. I. E. Infância e maquinarias. 2001. Tese (Doutorado em Educação) Universidade Federal do Rio Grande, Rio Grande, 2001.

${ }^{2}$ CASTRO, E. Vocabulário de Foucault: um percurso pelos temas, conceitos e autores. Belo Horizonte: Autêntica, 2009.

${ }^{3}$ FOUCAULT, M. Vigiar e punir: o nascimento da prisão. Petrópolis: Vozes, 1994.

Conexões: revista da Faculdade de Educação Física da UNICAMP, Campinas, v. 12, n. 1, p. 107-125, jan./mar. 2014. ISSN: 1983-9030 
${ }^{4}$ FOUCAULT, M. A governamentalidade. Rio de Janeiro: Graal, 1992.

${ }^{5}$ FOUCAULT, M. História da sexualidade II: o uso dos prazeres. Rio de Janeiro: Graal, 1998.

${ }^{6}$ BUJES, M. I. E. O fio e a trama: as crianças nas malhas do poder. Educação e Realidade, Porto Alegre, v. 25, n. 1, p. 25-44, 2000.

${ }^{7}$ BRASIL. Ministério da Educação e do Desporto. Referencial curricular nacional para a educação infantil. Brasília, 1998.

${ }^{8}$ BRASIL. Ministério da Educação e do Desporto. Critérios para um atendimento em creches que respeite os direitos fundamentais das crianças. Brasília, 2009.

${ }^{9}$ MESOMO, A. C. Educação Infantil: indagando sobre as práticas escolarizantes. 2004. Dissertação (Mestrado em Educação) - Universidade de São Paulo, São Paulo, 2004.

Recebido em: 15 ago. 2013

Aceito em: 27 fev. 2014

Contato: Marcos Garcia Neira mgneira@usp.br 